\title{
Intravenous methylprednisolone for multiple sclerosis in relapse
}

\author{
MP BARNES, DE BATEMAN, PG CLELAND, DJ DICK, TJ WALLS, PK NEWMAN, \\ M SAUNDERS, PJB TILLEY
}

From the Department of Neurology, Middlesbrough General Hospital, Middlesbrough, Cleveland, UK

SUMMARY A randomised comparison is made between methylprednisolone, $1 \mathrm{~g}$ intravenously daily for 7 days, and a standard ACTH regime for the treatment of multiple sclerosis in acute relapse. It is found that methylprednisolone produces a more rapid clinical improvement than ACTH but confers no longer term benefit when the two treatments are compared at 3 months. It is proposed that intravenous methylprednisolone does have a role to play in the management of a patient with an acute relapse of multiple sclerosis.

In the earlier stages of multiple sclerosis morbidity may be reduced by the judicious use of a short course of steroids during an acute relapse. Both intramuscular $\mathrm{ACTH}^{1}$ and oral prednisolone ${ }^{2}$ have been shown to decrease the duration of an exacerbation of multiple sclerosis but no long term benefit follows and more prolonged steroid treatment is usually ineffective. ${ }^{3}$

Recent reports ${ }^{4-6}$ have suggested that pulsed therapy with large doses of methylprednisolone may be effective in relapsing multiple sclerosis. This communication presents a randomised comparison of methylprednisolone with a standard ACTH regime.

\section{Methods}

Patients with clinically definite multiple sclerosis according to the criteria of McAlpine ${ }^{7}$ who presented to the Department of Neurology at Middlesbrough General Hospital in acute relapse were considered for inclusion in the trial. Relapse was defined as a symptomatic deterioration within the previous 4 weeks and no patient was improving spontaneously on entry. Each patient gave fully informed consent before randomisation to receive either intravenous methylprednisolone $1 \mathrm{~g}$ by slow injection daily for 7 days,

Address for reprint requests: Dr MP Barnes, Department of Neurology, Royal Victoria Infirmary, Queen Victoria Road, Newcastle upon Tyne, NE1 4LP, UK.

Received 7 February 1984 and in final form 10 July 1984 Accepted 14 July 1984 or intramuscular ACTH, 80 units, 60 units, 40 units and then 20 units daily, each for 7 days. All patients were admitted to hospital for one week and received physiotherapy as appropriate. Clinical assessments were made by a "blind" examiner on days $0,3,7,28$ and at 3 months using the Kurtzke disability status scale. ${ }^{8}$ In addition patients were weighed, blood pressure recorded and the presence of any objective or subjective steroid-induced side effects were noted. Plasma sugar and electrolyte levels were recorded at each assessment.

\section{Results}

Twenty five patients were randomised in total, 14 received methylprednisolone and 11 received ACTH. The table illustrates the age, sex, disease duration and disability at presentation of both groups. The effect of the two treatment regimes is illustrated in the figure. This shows that the methylprednisolone group improved faster than the ACTH group over the first 3 days and that this difference was maintained at Day 28. However, at 3 months there was no longer any significant difference between the two groups.

There were no differences between the groups with regard to side-effects, weight gain, blood pressure or plasma sugar and electrolyte levels. No serious side effects were found with either treatment regime in the trial patients but the Discussion draws the attention to potential problems associated with methylprednisolone in the light of wider, uncontrolled, experience with the drug. 
Table

\begin{tabular}{|c|c|c|}
\hline & $\begin{array}{l}\text { Methylprednisolone } \\
\text { Group }(n=14)\end{array}$ & $\begin{array}{l}\text { ACTH Group } \\
(n=11)\end{array}$ \\
\hline $\begin{array}{l}\text { Age mean } \pm 1 \mathrm{SD}(\mathrm{yr}) \\
\text { (range) } \\
\text { Sex female:male }\end{array}$ & $\begin{array}{l}36 \cdot 9 \pm 7 \cdot 9 \\
(23-51) \\
9: 5\end{array}$ & $\begin{array}{l}35 \cdot 0 \pm 10 \cdot 9 \\
(28-64) \\
6: 5\end{array}$ \\
\hline $\begin{array}{l}\text { Disease duration (yr) } \\
\text { mean } \pm 1 \mathrm{SD} \\
\text { (range) } \\
\text { Kurtzke Score at }\end{array}$ & $\begin{array}{l}8 \cdot 2 \pm 6 \cdot 2 \\
(1-18)\end{array}$ & $\underset{(1-13)}{5 \cdot 2 \pm 4 \cdot 2}$ \\
\hline $\begin{array}{l}\text { presentation } \\
\text { mean } \pm 1 \mathrm{SD} \\
\text { (range) }\end{array}$ & $\begin{array}{l}3 \cdot 9 \pm 1 \cdot 7 \\
(2-7)\end{array}$ & $\begin{array}{l}4 \cdot 4 \pm 2 \cdot 5 \\
(2-8)\end{array}$ \\
\hline
\end{tabular}

SD = Standard deviation

Discussion

Short term steroid therapy of acute relapse in multiple sclerosis is of marginal but proven benefit and yet the dosage, duration and route of administration has been almost arbitary."

In recent years there have been reports of the efficacy of intravenous "pulse" methylprednisolone for acute multiple sclerosis relapse. ${ }^{4-610}$ Dowling et $a l^{4}$ found a rapid clinical response in five of seven patients treated with $150 \mathrm{mg}$ of methylprednisolone intravenously every 6 hours for two days, followed by high dose oral prednisolone for up to three months. Uncontrolled data published by Buckley et $a l^{5}$ and by ourselves, ${ }^{6}$ using a higher dose intravenous regime, has also suggested a rapid clinical response.

This small study has confirmed the more rapid clinical response that occurs with methylprednisolone but fails to show any significant longer term benefit when compared to the conventional ACTH regime. This is in keeping with clinical impressions gained in this Department during the administration of more than 150 courses of methylprednisolone to more than 100 patients with relapsing multiple sclerosis.

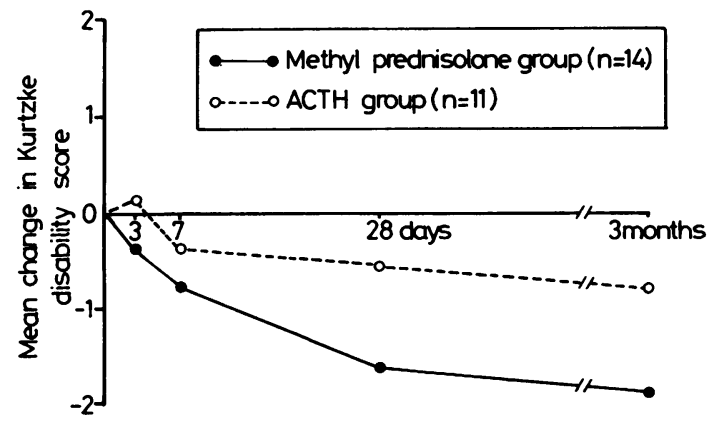

Fig Effect of treatment on Kurtzke disability score using Welch's test. Significant differences $(p<0.05)$ are seen when comparing the change from day 0 to day 3 and from day 0 to day 28.
We feel this therapy should not be given when there is a history of epilepsy or of concomitant infection nor would we use this treatment in the presence of a significant acquired organic mental deficit. The latter point follows the occurrence of a psychotic reaction in one patient, not part of the trial, who had previously shown signs of organic mental impairment. Common minor complaints are of a metallic taste during the injection and of transient facial flushing. A steroid "letdown" seen in some cases may be obviated by a short course of oral prednisolone to tail off the intravenous course.

The mode of action of methylprednisolone and of steroids generally is unclear. It may be supposed that such a rapid response is due simply to reduction of inflammation and oedema in the acute demyelinating lesion but it is of interest that Trotter and Garvey ${ }^{10}$ found disappearance of oligoclonal banding in four out of 12 patients given methylprednisolone. This may imply an immunological effect on cerebrospinal fluid IgG synthesis.

Preliminary studies of the use of shorter courses of methylprednisolone, $1 \mathrm{~g}$ intravenously for 3 or 4 days, have suggested that such regimes may be equally effective. We would regard this treatment as safe to be given on an out-patient or supervisede domiciliary basis.

Our results in this small scale trial must be regarded as preliminary. However, we feel that theo rapid clinical response induced by methylprednisolone indicates that this treatment does have a role to play in the management of the acute relapse in multiple sclerosis.

\section{References}

' Rose AS, Kuzma JW, Kurtzke JF et al. Cooperative study in the evaluation of therapy in multiple sclerosis: ACTH vs placebo. Final report. Neurology (Minneap) 1970;20:1-59.

${ }^{2}$ Eadie MJ, Tyrer JH. Neurological Clinical Pharmacology, Lancaster. MTP Press, International Medical Publishers, 1980.

${ }^{3}$ Millar JHD, Vas CJ, Noronha MJ et al. Long term treatment of multiple sclerosis with corticotrophin. Lancet 1967; ii:429-31.

${ }^{4}$ Dowling PC, Bosch VV, Cook SD. Possible beneficial effect of high dose intravenous steroid therapy in acute demyelinating disease and transverse myelitis. Neurology (Minneap) 1980;30:33-6.

${ }^{5}$ Buckley C, Kennard C, Swash M. Treatment of acute exacerbations of multiple sclerosis with intravenous methylprednisolone. J Neurol Neurosurg Psychiatry 1982;45:179-86.

${ }^{\circ}$ Newman PK, Saunders M, Tilley PJB. Methylprednisolone therapy in multiple sclerosis. J Neurol Neurosurg Psychiatry 1983;46:941-2. 
${ }^{7}$ McAlpine DM, Lumsden CE, Acheson EG. Multiple Sclerosis: a Reappraisal. 2nd ed, Baltimore, Williams and Wilkins 1972.

${ }^{8}$ Kurtzke JF. Further notes on disability evaluation in multiple sclerosis with scale modification. Neurology (Minneap) 1965;15:654-61.

" Tourtellotte WW, Baumhefner RW, Potvin JH et al.
Comprehensive management of multiple sclerosis. In: Hallpike JF, Adams CMW, Tourtellotte WW (eds), Multiple Sclerosis, London, Chapman and Hall, 1983:513-78.

${ }^{10}$ Trotter JL, Garvey WF. Prolonged effects of large dose methylprednisolone infusion in multiple sclerosis. Neurology (Minneap) 1980;30:702-8. 